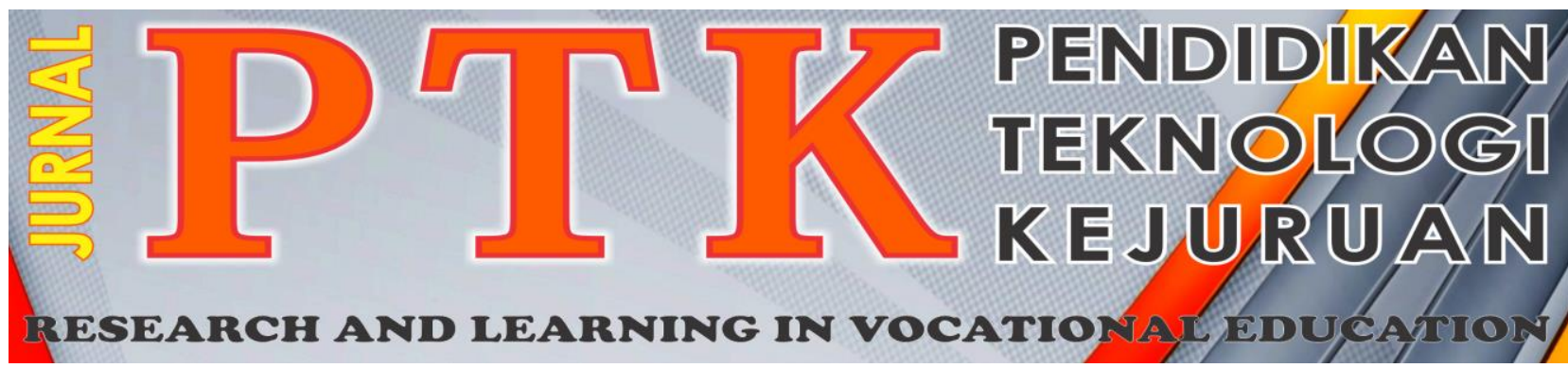

Vol. 2, No. 4, 2019

P-ISSN: 2621-3273

E-ISSN: 2621-1548

\title{
Perancangan Sistem Informasi Bencana di Kabupaten Padang Pariaman
}

\author{
Elmawati $^{1 *}$ dan Veni Wedyawati ${ }^{1}$ \\ ${ }^{1}$ Jurusan Sistem Informasi, Sekolah Tinggi Teknologi Industri Padang \\ ${ }^{*}$ Corresponding author, e-mail: elmawati@sttind.ac.id ${ }^{1}$
}

\begin{abstract}
Abstrak - Bencana alam tidak dapat kita ketahui dengan cepat, banyaknya kerusakan infrastuktur yang terjadi sehingga kesulitan mendapatkan informasi yang akurat. Badan Penanggulangan Bencana Daerah Kabupaten Padang Pariaman sering kesulitan dalam mengolah data bencana yang ada karena belum adanya sistem yang baik dalam mengolah data tersebut. Dengan adanya sistem informasi yang berbasis web ini dapat memberikan informasi bencana dengan cepat dan tepat serta penangan korban bencana dengan tepat juga pada daerah Kabupaten Padang Pariaman. Sistem ini dibuat dengan menggunakan bahasa pemrograman PHP yang merupakan bahasa pemrograman yang bersifat open source.
\end{abstract}

Kata kunci：Bencana, PHP

Abstract-Disasters not we can know quickly because of the damage going on that trouble getting precise information. Badan Penanggulangan Bencana Daerah Kabupaten Padang Pariaman often difficulty in process data disaster that is because there is no system quickly in process the data. With the information systems that webbased this can provide disaster victim management a quick and exact in convey information about disasters that happened to the areas Kabupaten Padang Pariaman. This system will be made in use of language programming PHP that is a programming language is open source.

Keywords: Disasterc, PHP

\section{Pendahuluan}

Secara geologis Kabupaten Padang Pariaman terletak pada jalur patahan lempengan dunia yaitu Lempengan Eurasia dan Lempeng Indo-Australia dan topologi Padang Pariaman yang dilalui oleh banyak anak sungai, Kabupaten Padang Pariaman merupakan kawasan yang rawan bencana, bentuk bencana yang pernah dan mungkin terjadi di Kabupaten Padang Pariaman identik dengan kondisi alam tersebut yaitu bencana gempa bumi dan tsunami, banjir, kebakaran, tanah longsor, angin badai atau putting beliung, abrasi pantai dan lainlain. Selain faktor alam Kabupaten Padang Pariaman juga termasuk rawan bencana yang timbul akibat ulah manusia yang disebabkan kurang memperhatikan keseimbangan dan kelestarian lingkungan serta kelalaian dari manusia yang berakibat bencana.

Kabupaten Padang Pariaman memiliki wilayah yang luas yaitu 17 Kecamatan, 60 Nagari, dalam Penyampaian Informasi Bencana dikelola oleh
Bidang Kedaruratan dan Logistik setiap terjadi bencana data diambil oleh staf bidang kedaruratan dan logistik sehingga bisa dengan cepat diberikan bantuan baik bantuan logistik maupun pertolongan kedaruratan seperti pembersihan lokasi, pencarian korban sampai mendirikan tempat tinggal sementara.

Pengolahan informasi berbasis komputer mampu menghasilkan informasi yang akurat, tepat dan efektif serta memberikan begitu banyak manfaat bagi Kantor Badan Penanggulangan Bencana Daerah Kabupaten Padang Pariaman dalam mencapai tujuannya yaitu mempermudah proses kerja dalam pengolahan data di kantor tersebut. Pengolahan data menggunakan teknologi komputer perlu adanya suatu program yang dapat membantu proses pengolahan data yang ada pada suatu kantor. Demi mewujudkan kemudahan dalam kinerja, pengolahan data diperlukan sebagai pengelolaan Sumber Daya Manusia yang baik dan benar serta dibantu atau didukung dengan perangkat komputer 
dalam pengolahan data agar menghasilkan informasi yang akurat.

Pada Badan Penanggulangan Bencana Daerah Kabupaten Padang Pariaman pengolahan data bencana sudah menggunakan komputerisasi berupa Microsoft Office tetapi belum efektif dan membutuhkan waktu yang lama sehingga perlu adanya pengembangan dengan menggunakan Sistem Informasi baru yaitu dengan menggunakan Pemrograman PHP atau berbasis website.

\section{Studi Pustaka}

\subsection{Konsep Dasar Sistem Informasi}

Pentingnya informasi digunakan dalam manajemen sebagai alat dalam pengambilan keputusan. Tidak hanya itu tetapi juga digunakan untuk mengetahui perkembangan organisasi dan lingkungan serta untuk perencanaan strategis untuk masa yang akan datang. Sistem yang tidak memperhatikan perkembangan informasi akan menjadi kerdil dan akhirya akan berakhir. Informasi diperoleh dari sistem informasi (information system). (Jogiyanto:2009) ${ }^{(2)}$.

\subsection{Konsep Dasar Pengembangan Sistem Informasi}

\subsubsection{Pengertian Pengembangan Sistem}

Pengembangan sistem atau lebih dikenal dengan rekayasa adalah suatu perancangan (arsitek) dari pada suatu sistem yang lama kepada bentuk yang baru dan lebih optimal penggunaannya. (Hasta:2004) $^{(6)}$.

\subsubsection{Perancangan Sistem}

Berikut ini adalah tahapan-tahapan yang dilakukan untuk merancang suatu sistem :

1. Mendefinisikan masalah.

2. Analisis masalah.

3. Perancangan global.

4. Perancangan detail.

5. Membuat Program.

6. Testing.

7. Implementasi.

8. Evaluasi.

9. Dokumentasi

\subsubsection{Sasaran Perancangan Sistem}

Sasaran-sasaran yang akan dicapai dalam perancangan suatu sistem adalah:

1. Perancangan sistem harus berguna, mudah dipahami dan nantinya mudah digunakan.

2. Perancangan sistem harus dapat mendukung tujuan utama. a. Perancangan sistem harus efisien dan efektif untuk dapat mendukung pengolahan data

b. Perancangan sistem harus dapat mempersiapkan rancangan bangunan yang terinci untuk masing-masing komponen dari sistem informasi.

\subsection{Alat Bantu dalam Perancangan \\ Sistem}

Langkah-langkah yang dilakukan pada tahap merancang suatu sistem dan program adalah membuat usulan pemecahan masalah secara logika. Alat bantu yang digunakan antara lain adalah :

\subsubsection{UML (Unified Modeling Language)}

Gambaran umum mengenai UML dapat dijelaskan berdasarkan kegunaan dari UML itu sendiri, yaitu. (Munawar.2005:109) ${ }^{(4)}$

\section{Modeling Language}

UML merupakan bahasa pemodelan yang memiliki pembendaharaan kata dan cara untuk mempresentasikan secara fokus dan konseptual dan fisik dari suatu sistem.

\section{Visualizing}

UML tidak hanya merupakan rangkaian simbol grafikal, cukup dengan tiap simbol pada notasi UML merupakan penetapan semantik yang baik.

\section{Specifying}

UML menunjukan semua spesifikasi keputusan analisis, desain dan implementasi yang penting yang harus dibuat pada saat pengembangan dan penyebaran dari sistem perangkat lunak intensif

\section{Constructing}

UML bukan bahasa pemrograman visual, tetapi model UML dapat dikoneksikan secara langsung pada bahasa pemrograman visual atau tabel pada database relational atau peyimpangan tetap pada database berorientasi objek.

\section{Documenting}

Maksudnya UML menunjukan dokumentasi dari arsitektur sistem dan detail dari semuanya. UML menyediakan bahasa untuk memodelkan aktifitas dari perancangan proyek dan manajemen perlepasan.

\subsubsection{Bagian-bagian UML}

Bagian-bagian utama dari UML adalah view, diagram, model element, dan general mechanism.

\section{a. View}

View digunakan untuk melihat sistem yang dimodelkan dari beberapa aspek yang berbeda. 


\section{Use case View}

Mendeskripsikan fungsi sistem yangs seharusnya dilakukan sesuai yang diinginkan external actors.view ini digunakan terutama untuk pelanggan, perancang (designer), pengembang (developer), dan penguji sistem (tester).

\section{Logical View}

Mendeskripsikan bagaimana fungsi dari sistem struktur statis (class, object, dan relationship) dan kolaborasi dinamis yang terjadi ketika object mengirim pesan ke object lain dalam suatu fungsi tertentu.

\section{Concurrency View}

Membagi sistem ke dalam proses dan prosessor. View ini digambarkan dalam diagram dinamis (state, sequence, collaboration, dan activity diagrams) dan diagram implementasi (component dan deployment diagrams).

\section{Component View}

Komponen yang merupakan tipe lainnya dari code module diperlihatkan dengan struktur dan ketergantungannya juga alokasi sumber daya komponen dan informasi administrative lainnya. View ini digambarkan dalam component view dan digunakan untuk pengembang (developer).

\section{Deployment View}

Mendeskripsikan fisik dari sistem seperti komputer dan perangkat (nodes) dan bagaimana hubungannya dengan lainnya. View ini digambarkan dalam deployment diagrams dan digunakan untuk pengembang (developer), pengintegrasi (integrator) dan penguji (tester).

\section{a. Diagram}

Diagram berbentuk grafik yang menunjukan simbol elemen model yang disusun untuk mengilustrasikan bagian atau aspek tertentu dari sistem. Adapun jenis diagram antara lain:

\section{Use case Diagram}

Use case diagram adalah deskripsi fungsi dari sebuah sistem dari perspektif penggguna. Use case diagram bekerja dengan cara mendeskripsikan tipikal interaksi antara user sebuah sistem dengan sistemnya sendiri melalui sebuah cerita bagaimana sebuah sistem dipakai (Munawar, 2005:63).

\section{Class Diagram}

Class Diagram adalah deskripsi kelompok obyekobyek dengan properti, perilaku dan relasi yang sama. Sehingga dengan adanya class diagram dapat memberikan pandangan global atas sebuah sistem.

\section{Activity Diagram}

Activity diagram adalah teknik untuk mendiskrispikan logika procedural,dan aliran kerja dalm banyak kasus

\section{Deployment Diagram}

Deployment diagram menunjukkan tata letak sebuah sistem secara fisik, menampakkan bagianbagian software yang berjalan pada bagian hardware. Deployment diagram menyediakan gambaran bagaimana sistem secara fisik akan terlihat.

\subsection{Konsep Dasar Pemrograman}

PHP dan database MySQL merupakan suatu bentuk produk dari open source, yang gratis yang dapat digunakan siapapun tanpa ada membayar lisensi dari produk tersebut..

\subsection{Konsep Manajemen Database}

\subsubsection{Pengertian Database}

Pengertian database dilihat dari istilah database itu sendiri, mengandung arti bahwa :

1. Kumpulan data dalam jumlah besar, disimpan dalam media penyimpanan skunder (disk, hardisk, magnetic tape dan lain-lain).

2. Berkenan dengan kumpulan data tersebut, terdapat seperangkat program aplikasi, biasanya melakukan operasi retrieve, update, delete dan insert.

3. Kumpulan data yang benar dan terstruktur dari database yang mengandung integritas.

Dalam hal ini database merupakan media penyimpanan elektronik yang mampu manajemen keselutuhan. Arsip dengan aturan yang bisa disesuaikan dengan kebutuhan (Kadir:2018) ${ }^{(3)}$

\subsubsection{Database MySQL}

MySQL adalah Relational Database Management System (RDBMS) yang didstribusiakn secara gratis di bawah lisensi GPL (General Public License). MySQL sebenarnya merupakan turunan salah satu konsep utama dalam database sejak lama yaitu SQL (Structured Query Language). SQL adalah sebuah konsep pengoperasian database, terutama untuk pemilihan / seleksi dan pemasukan data, yang memungkinkan pengoperasian data dikerjakan dengan mudah secara otomatis. Sebagai database server, MySQL dapat dikatakan lebih unggul dibandingkan databae server lainnya dalam query data. Hal ini terbukti untuk query yang dilakukan oleh single user, kecepatan query MySQL bisa sepuluh kali lebih cepat dari PostfreSQL dan lima kali lebih cepat dibandingkan Interbase. 


\subsection{Bencana}

Menurut Kamus Besar Bahasa Indonesia, bencana mempunyai arti sesuatu yang menyebabkan atau menimbulkan kesusahan, kerugian atau penderitaan. Sedangkan bencana alam artinya adalah bencana yang disebabkan oleh alam (Purwadarminta, 2006) $^{(5)}$.

Bencana alam adalah bencana yang diakibatkan oleh peristiwa atau serangkaian peristiwa yang disebabkan oleh gejala-gejala alam yang dapat mengakibatkan kerusakan lingkungan, kerugian materi, maupun korban manusia

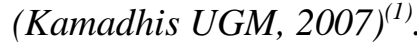

Jenis-jenis bencana menurut UndangUndang No.24 Tahun 2007, antara lain :

1. Bencana alam

2. Bencana non alam

3. Bencana sosial (UU RI, 2007) ${ }^{(7)}$.

\section{METODOLOGI PENELITIAN}

Jenis penelitian yang penulis lakukan adalah penelitian lapangan (Field research). Pada penelitian lapangan ini penulis melakukan peninjauan di Badan Penanggulangan Bencana Daerah Kabupaten Padang Pariaman untuk mendapatkan data-data yang akurat. Langkah-langkah penelitian yaitu observasi dan wawancara. Sumber data ada sumber data primer dan sumber data sekunder.

\section{HASIL DAN PEMBAHASAN}

\section{Pengertian dan Tujuan Implementasi \\ Sistem}

Implementasi sistem adalah prosedur yang dilakukan pada tahap sistem dalam dokumen yang sedang disetujui dan menguji kemudian menginstall dan menggunakan program yang dibuat, penerapan sistem baru ini akan diterapkan secara menyeluruh.

Tujuan dari implementasi sistem adalah :

1. Menyelesaikan desain sistem yang ada dalam dokumen sistem yang disetujui.

2. Menulis, menguji dan mendokumentasikan program dan prosedur-prosedur yang diperlukan oleh dokumen desain sistem yang diuji.

3. Memastikan bahwa personal dapat mengoperasikan sistem yang telah dibuat.

4. Memastikan bahwa konversi ke sistem yang baru berjalan dengan benar.

5. Memperhitungkan bahwa sistem sesuai dengan kebutuhan pemakai.

\section{Tahapan Implementasi Sistem}

Tahapan dalam implementasi sistem ada tiga, yaitu :
1. Perencanaan dan proses implementasi

Perencanaan dan proses implementasi merupakan langkah penting dalam penerapan sebuah sistem baru. Tujuan dari pemberlakuan proses ini adalah agar penerapan sistem baru ini betul-betul sesuai dengan tujuan dan sasaran pengadaannya.

\section{Pelaksanaan proses implementasi}

Pelaksanaan proses implementasi bertujuan untuk melakukan proses penerapan sistem baru.

3. Pelatihan Personil

Pelatihan personil dilakukan dengan tujuan agar personil yang ditunjuk untuk menjalankan sistem baru tidak mengalami kesulitan dalam pengoperasiannya.

\section{Pemrograman}

Penulisan program dalam bahasa komputer, dalam hal ini menggunakan $P H P$ kemudian proses menjalankan program untuk melakukan pengujian program.

1. Halaman Utama

Halaman ini terdiri dari logo dan informasi kejadian bencana yang dapat dilihat oleh user yang telah mengakses alamat website http://www.bpbdpadangpariaman.info. Tampilan halaman utama seperti tampak pada Gambar 1.

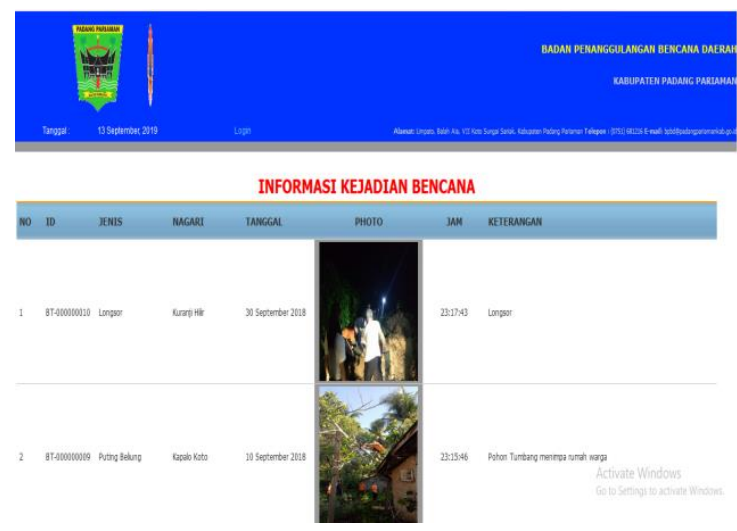

Gambar 1. Halaman Utama

2. Halaman Berita

Pada halaman ini ditampilkan informasi mengenai informasi kejadian bencana yaitu gambar dan detail kejadian bencana. Tampilan halaman ini dapat dilihat pada Gambar 2. 


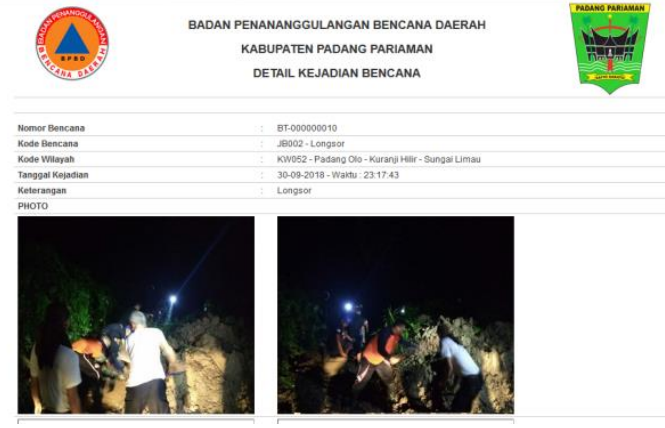

Gambar 2. Halaman Berita

3. Halaman Login

Untuk masuk ke sistem user harus login. Pada halaman login ini akan menentukan apa masuk ke sistem sebagai user atau admin. Jika sebagai user maka dapat melihat data informasi bencana sedangkan jika sebagai admin dapat mengelola semua sistem. Untuk masuk ke sistem maka harus menginputkan username dan password, seperti pada Gambar 3.

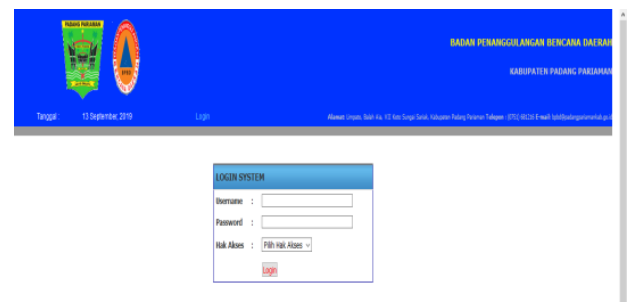

Gambar 3. Halaman Login

4. Halaman Admin

Administrator melakukan input dan edit pada menu tersendiri dan hanya dapat diakses oleh Administrator. Tampilan halaman Administrator dapat dilihat pada Gambar 4.

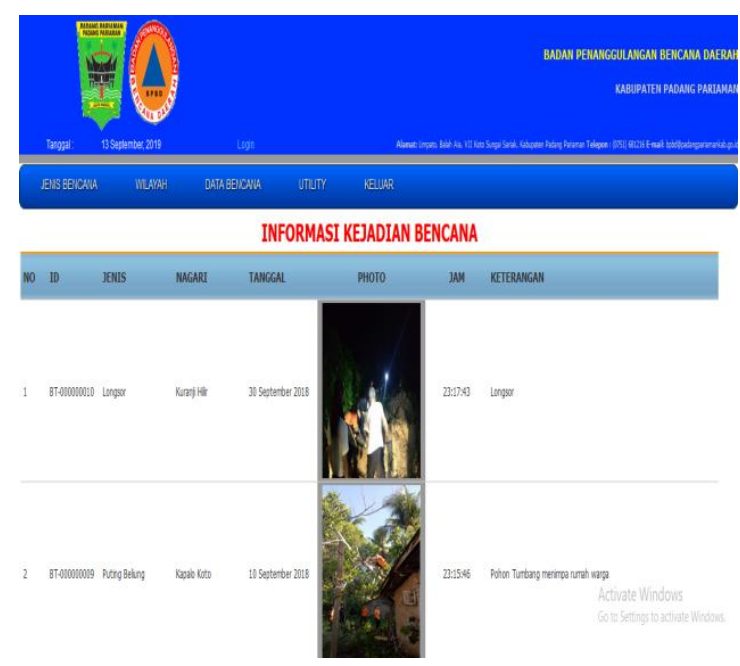

Gambar 4. Halaman Administrator
5. Halaman Input Data Jenis Bencana

Untuk mengisi data jenis bencana, maka admin mengisi panel kode bencana, jenis bencana, dan keterangan. Setelah data terisi dengan benar, maka admin akan menyimpannya ke dalam server dengan mengklik tombol simpan. Untuk mengisi lagi maka admin dapat melakukan langkah yang sama. Tampilan halaman input data jenis bencana dapat dilihat pada Gambar 5

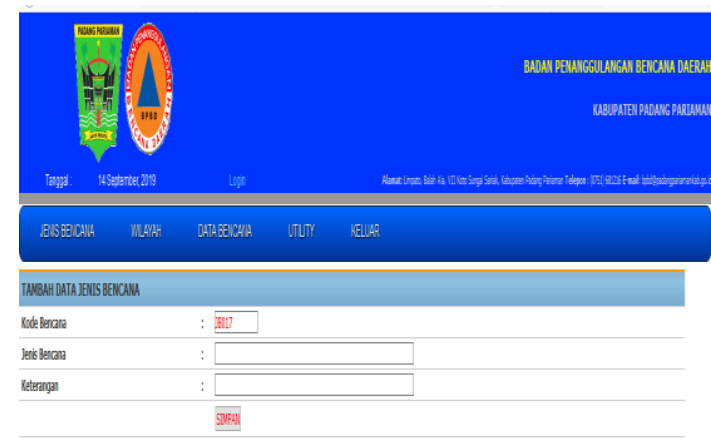

\section{Gambar 5. Halaman Input Data Jenis Bencana}

6. Halaman Output Data Jenis Bencana

Hasil pengisian data jenis bencana yang telah disimpan oleh admin akan ditampilkan sesuai dengan banyaknya data inputan. Data jenis bencana yang telah disimpan, untuk melihat output jenis bencana maka admin akan mengklik data jenis bencana pada panel. Tampilan halaman output jenis bencana dapat dilihat pada Gambar 6 .

DATA JENIS BENCANA

GAdd Dato

\begin{tabular}{|c|c|c|c|c|c|}
\hline № & Kode & Jenis Bencana & Keterangan & Edit & Dekte \\
\hline 1 & 18001 & Banji Bandang & Baxif banctang & ? & $\mathcal{x}$ \\
\hline 2 & 18002 & Longsor & Longsor & 2 & 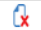 \\
\hline 3 & 18003 & Putring Being & Putring Beling & 2 & $Q$ \\
\hline 4 & 10004 & Gerpo Buri & Gempa Buri & ? & $\hat{x}$ \\
\hline 5 & 18005 & Tengegern & Tengogem & ? & Q \\
\hline 6 & 18006 & Sarbar Pett/anca Estom & Sarbar Pett/Curca Estim & 2 & $Q$ \\
\hline 7 & 18007 & Tarah Longsor & Tanah Longsor & ? & $Q$ \\
\hline 8 & 18008 & 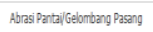 & Abras Panta/Geartiongng Pasang & ? & $Q$ \\
\hline 9 & 18009 & Bajir & Banif & ? & Q \\
\hline 10 & 18010 & Orang hieng a Hutor & Orang hibng dilituan & 2 & $Q$ \\
\hline 11 & 10011 & Tengogebn di Sungai & Tenggetema i Sungà & 2 & $Q$ \\
\hline 12 & 10012 & Tengegern nil zaut. & Tenggebm di lat. & $?$ & $x$ \\
\hline
\end{tabular}

\section{Gambar 6. Halaman Output Data Jenis Bencana}

7. Halaman input Data Kecamatan

Untuk mengisi data kecamatan, maka admin mengisi panel kode kecamatan, nama kecamatan. Setelah data terisi dengan benar, maka admin akan menyimpannya ke dalam server dengan mengklik tombol simpan. Untuk mengisi lagi maka admin dapat melakukan langkah yang sama. Tampilan halaman input data kecamatan dapat dilihat pada Gambar 7. 


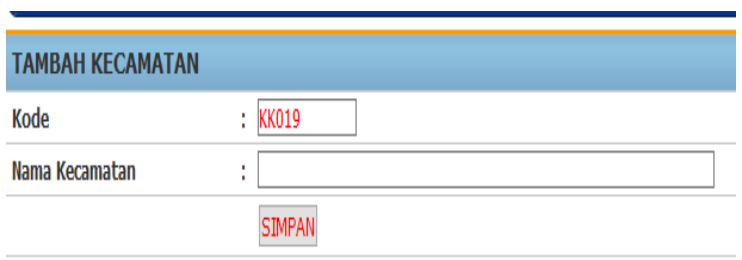

Gambar 7. Halaman Input Kecamatan

8. Halaman Output Data Kecamatan

Hasil pengisian data kecamatan yang telah disimpan oleh admin akan ditampilkan sesuai dengan banyaknya data inputan. Data kecamatan yang telah disimpan, untuk melihat output kecamatan maka admin akan mengklik data kecamatan pada panel. Tampilan halaman output kecamatan dapat dilihat pada Gambar 8.

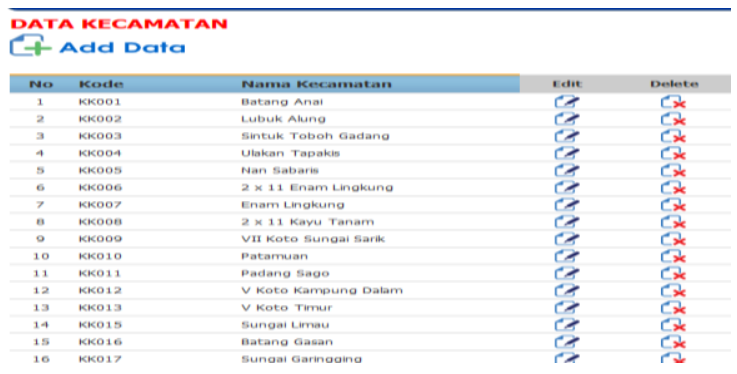

Gambar 8. Halaman Output Kecamatan

9. Halaman Input Data Wilayah

Untuk mengisi data wilayah, maka admin mengisi panel kode wilayah, korong, nagari, dan kecamatan. Setelah data terisi dengan benar, maka admin akan menyimpannya ke dalam server dengan mengklik tombol simpan. Untuk mengisi lagi maka admin dapat melakukan langkah yang sama. Tampilan halaman input wilayah dapat dilihat pada Gambar 9.

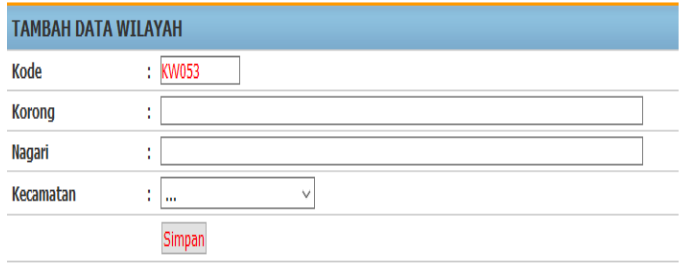

Gambar 9. Halaman Input Wilayah

\section{Halaman Output Wilayah}

Hasil pengisian data wilayah yang telah disimpan oleh admin akan ditampilkan sesuai dengan banyaknya data inputan. Data wilayah yang telah disimpan, untuk melihat output wilayah maka admin akan mengklik data wilayah pada panel. Tampilan halaman output wilayah dapat dilihat pada Gambar 10.

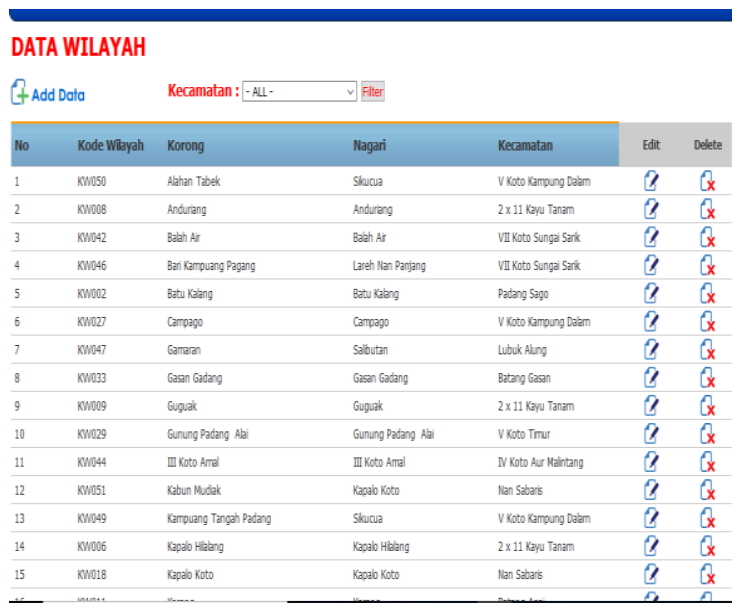

Gambar 10. Halaman Output Wilayah

\section{Halaman Input Data Bencana Kejadian}

Untuk mengisi data bencana kejadian, maka admin mengisi panel no bencana, kode bencana, kode wilayah, tanggal kejadian, keterangan, dan upload photo kejadian. Setelah data terisi dengan benar, maka admin akan menyimpannya ke dalam server dengan mengklik tombol simpan. Untuk mengisi lagi maka admin dapat melakukan langkah yang sama. Tampilan halaman input data bencana kejadian dapat dilihat pada Gambar 11.

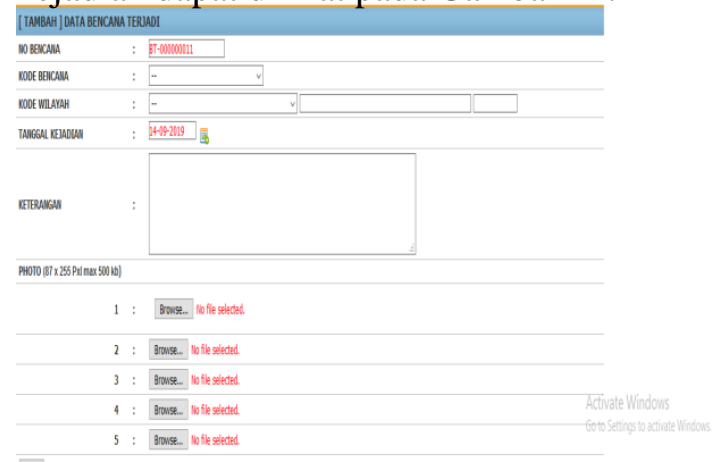

\section{Gambar 11. Halaman Input Data Bencana Kejadian}

\section{Halaman Output Data Bencana Kejadian}

Hasil pengisian data bencana kejadian yang telah disimpan oleh admin akan ditampilkan sesuai dengan banyaknya data inputan. Data bencana kejadian yang telah disimpan, untuk melihat output data bencana kejadian maka admin akan mengklik data bencana kejadian pada panel. Tampilan halaman output data bencana kejadian dapat dilihat pada Gambar 12. 


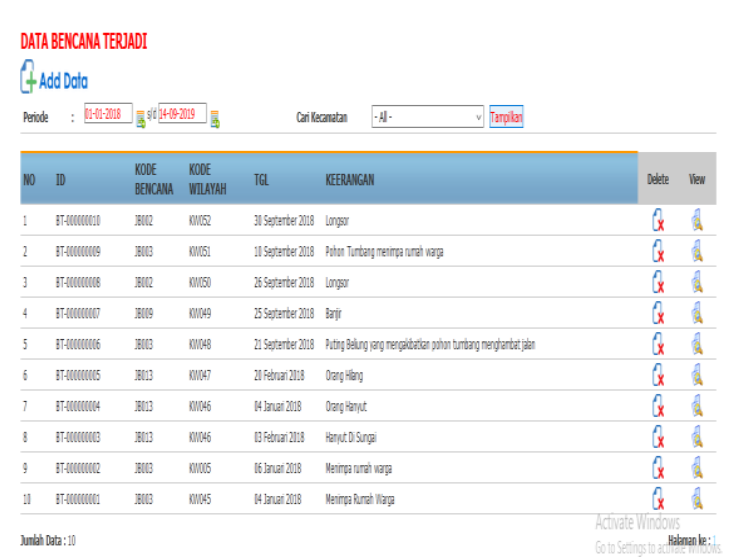

\section{Gambar 12. Halaman output Data Bencana Kejadian}

13.Halaman Laporan Bencana Berdasarkan Bulan Kejadian

Untuk mencetak laporan bencana berdasarkan bulan kejadian maka admin akan memilih bulan dan tahun kemudian baru tekan tombol cetak. Tampilan cetak laporan bencana berdasarkan bulan kejadian dapat dilihat pada Gambar 13.

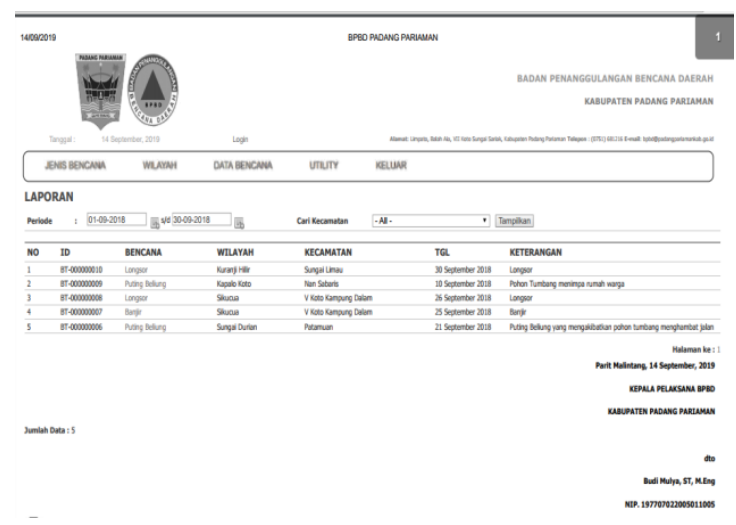

\section{Gambar 13. Halaman Cetak Laporan Bencana Bulan Kejadian}

14.Halaman Laporan Bencana Berdasarkan Tahun Kejadian

Untuk mencetak laporan bencana berdasarkan tahun kejadian maka admin akan memilih tahun kemudian baru tekan tombol cetak. Tampilan cetak laporan bencana berdasarkan tahun kejadian dapat dilihat pada Gambar 14.

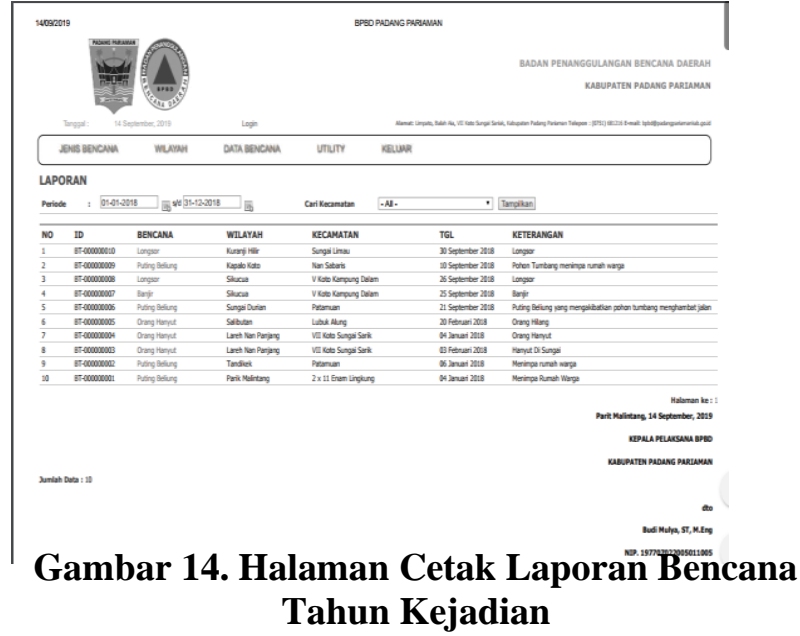

\section{KESIMPULAN}

1. Dengan adanya aplikasi bahasa pemrograman PHP untuk mengolah data bencana yang menggunakan database MYSQL sebagai tempat penyimpanan datanya, maka laporan pengolahan data bencana dapat dilakukan secara cepat dan akurat.

2. Menggunakan aplikasi ini, akan memberi suatu kemudahan pada Badan Penanggulangan Bencana Daerah Kabupaten Padang Pariaman dalam memperoleh informasi tentang bencana yang ada di Kabupaten Padang Pariaman.

\section{DAFTAR PUSTAKA}

[1] Buletin Kamadhis UGM, Bencana Alam, Yokyakarta. 2007

[2] Jogianto, 2009. Sistem Teknologi Informasi : Konsep Dasa, Teknologi, Aplikasi, Pengembangan dan Pengelolaan. Andi Offset, Yogyakarta.

[3] Kadir, Abdul, 2008, Belajar Database Menggunakan MySQL, Yogyakarta : Andi.

[4] Munawar, 2005. Pemodelan Visual Dengan UML. Graha Ilmu. Yogyakarta.

[5] Purwadarminta, 2006, Kamus Besar Bahasa Indonesia, Balai Pustaka.

[6] Putranta, Hasta Dewa. 2004. Pengantar Sistem dan Teknologi Informasi. Yogyakarta Amus.

[7] Undang-undang No. 24 Tahun 2007

\section{Biodata Penulis}

Elmawati, lahir di Siguntur Tua, 20 Oktober 1980. Menyelesaikan S1 pada Program Studi Sistem Informasi Sekolah Tinggi Teknologi Industri (STTIND) Padang tahun 2012 dan pendidikan Pascasarjana (S2) Magister Komputer Fakultas Ilmu Komputer Universitas Putra Indonesia "YPTK" pada tahun 2016. Sejak tahun 2016 menjadi staf pengajar tetap di Program Studi Sistem Informasi Sekolah Tinggi Teknologi Industri (STTIND) Padang. 
Veni Wedyawati, lahir di Sanggaran Agung, 15 September 1989. Menyelesaikan S1 pada Program Studi Sistem Informasi Fakultas Ilmu Komputer Universitas Putra Indonesia "YPTK" Padang tahun 2012 dan pendidikan Pascasarjana (S2) Magister Komputer
Fakultas Ilmu Komputer Universitas Putra Indonesia "YPTK" pada tahun 2013. Sejak tahun 2014 menjadi staf pengajar tetap di Program Studi Sistem Informasi Sekolah Tinggi Teknologi Industri (STTIND) Padang. 